\title{
Energy Balance and Evapotranspiration in a High Mountain Area during Summer
}

\author{
T. KONZELMANN
}

Department of Geography, Swiss Federal Institute of Technology, Zurich, Switzerland

\author{
P. Calanca
}

Swiss Federal Laboratories for Materials Testing and Research, Dubendorf, Switzerland

G. MÜllek, L. MENZEL, AND H. LANG

Department of Geography, Swiss Federal Institute of Technology, Zurich, Switzerland

12 August 1996 and 7 November 1996

\section{ABSTRACT}

\begin{abstract}
A meteorological experiment was carried out in summer 1995 at two representative sites above and below the timberline in the Dischma Valley, near Davos, Switzerland. The study aimed at investigating the characteristics of the surface energy balance and of the evapotranspiration in a high alpine environment during the vegetation period. At both sites, net radiation is the only energy source. It amounts to about $80 \mathrm{~W} \mathrm{~m}^{-2}$ at the lower and $100 \mathrm{~W} \mathrm{~m}^{-2}$ at the upper sites, respectively. Since the albedo and the longwave radiation budget do not differ significantly, net radiation was found to be linearly dependent on global radiation. The latent heat flux associated with evapotranspiration represents the most important energy sink, averaging to $-70 \mathrm{~W} \mathrm{~m}^{-2}$ at the lower and $-63 \mathrm{~W} \mathrm{~m}^{-2}$ at the upper locations. It is therefore of comparable magnitude, despite a larger energy availability at the upper site. This is due to a significantly larger Bowen ratio at this upper location. On the other hand, the diurnal course of the Bowen ratio is at both sites such that the latent heat flux can be expressed as a linear function of net or global radiation. For a better characterization, the actual evapotranspiration was compared to Penman's parameterization, which represents the potential limit for saturated surface conditions. The comparison shows that, even during wet periods, evapotranspiration is regulated by the moisture conditions in the soil and the physiological behavior of vegetation.
\end{abstract}

\section{Introduction}

In summer, the two dominant components of the energy budget over vegetated surfaces are net radiation and the latent heat flux associated with evapotranspiration (Oke 1987). In mountainous areas, as in other climatic regions, they are greatly influenced by the variability of physiographic conditions (LeDrew 1975; Staudinger and Rott 1981; Bailey et al. 1990; Barry 1992). For wet surfaces, evapotranspiration can be thought to be limited only by the available energy and aerodynamic conditions (Garratt 1992). When the surface is only partially saturated, evapotranspiration becomes actively controlled by the plant community. Namely, under such conditions, transpiration of water depends on the vapor concentration difference between the surrounding air and the leaves. Conceptually it can be thought to be regulated by soil, plant, and air resis-

Corresponding author address and current affliation: Dr. Thomas Konzelmann, Swiss Meteorological Institute, Krähbühlstr. 58, CH-8044 Zürich, Switzerland. tances. Of utmost importance is the stomatal resistance of the leaves, which shows large variations for various vegetation types (Körner and Mayr 1981).

Despite the necessity of a better understanding of the complex interactions between the various components of the energy and water budget in mountainous areas during the vegetation period, most investigations carried out in the past in the Alps have focused on ice- and snow-covered surfaces (Lang 1978; Plüss and Mazzoni 1994). Investigations focusing on the vegetation period are due to Rott (1979) and Hennemuth and Köhler (1984) in the alpine region and to Grebner and Brutsaert (1984) and Brutsaert and Kustas (1987) in the prealpine region. In these latter studies, emphasis was given to the hydrological aspects of small to regional catchment basins. The results have provided valuable information for modeling purposes (Gurtz et al, 1997). However, the generalization of such models to the whole alpine domain is still uncertain.

The aim of the present study is a careful examination of the energy budget and of the factors controlling evapotranspiration in a high region of the Alps during the vegetation period. To this purpose, a specific field 


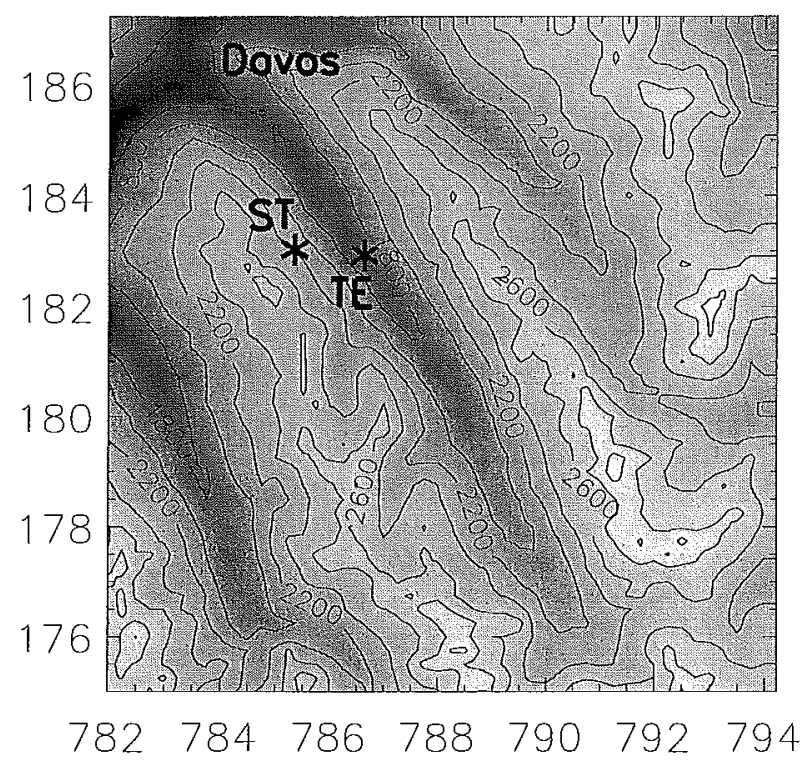

FIG. 1. Map of the Dischma Valley near Davos, Switzerland. Contour lines of altitude are given. Measuring sites: Stillberg (ST) located at the northeast-facing slope and Teufi (TE) located at the valley floor. Axis are given in coordinates based on the Swiss Coordination Grid. Unit is kilometers.

experiment was conducted in the Dischma Valley $\left(46^{\circ} 46^{\prime} \mathrm{N}, 9^{\circ} 53^{\prime} \mathrm{E}\right)$ near Davos, Switzerland. All energy balance components, as well as additional parameters, were measured at two representative sites above and below the timberline. The field campaign extended from 21 July to 7 September 1995, but only in August were both study sites operated simultaneously. Measurements of the energy fluxes were stopped at the end of August following the first snowfall events.

The layout of the paper is as follows. After a brief description of the site and of the prevailing meteorological conditions in section 2, methods and instrumental setup are presented in section 3. A discussion of the energy budget and its components is given in section 4. Evapotranspiration is examined in section 5. The main conclusions and some outlooks for future projects are the subject of section 6 .

\section{Study area and meteorological conditions}

The Dischma Valley (Fig. 1) is oriented from northnorthwest to south-southeast. The first site, Teufi, is located on the valley bottom at $1680 \mathrm{~m}$ MSL. The other one, Stillberg, is situated at the edge of a small plateau on the northeast-facing slope at $2220 \mathrm{~m}$ MSL. The horizontal distance between the two stations is $1.2 \mathrm{~km}$. A detailed meteorological and topographical description of the Stillberg area is given in Turner et al. (1975).

At Teufi the dominant vegetation type is meadow. This was cut just before the measurements were started. The plant community prevailing at Stillberg is dwarf shrubs, including Rhododendro-Vaccinietum. During the field campaign the growing rates were low at both sites. The surface texture is more heterogeneous at the upper site. Extended patches of vegetated surfaces interchange with bare soil and small isolated rocks. The soils are of the podsol type at both sites. The soil layer is about $50 \mathrm{~cm}$ thick at Teufi, but it barely attains 20 $\mathrm{cm}$ at Stillberg. At this upper site, single rocks and marked horizons were frequently observed in the soil layer.

During the last days of July and the first five days of August the weather was generally fine. The cloud amount averaged to $4 / 8$, and $10 \mathrm{~mm}$ of precipitation were recorded in these 10 days. The conditions changed on 6 August, when the first of a series of rainfall events lasting until the end of the month was recorded, giving a total of about $110 \mathrm{~mm}$ in 21 days. During this second phase, dry periods lasted at most for three consecutive days. The average total cloud amount was significantly higher, about $7 / 8$.

\section{Methods and instrumental setup}

The energy balance of a vegetated surface can be expressed as

$$
\mathrm{NR}+\mathrm{LE}+H+G=0,
$$

where NR is the net radiation, LE the latent heat flux associated both with evaporation and transpiration, $H$ the sensible heat flux, and $G$ the ground heat flux. All fluxes are taken positive when directed toward the surface, negative if directed away from the surface. The ratio of the sensible to the latent heat flux is know as the Bowen ratio $B$,

$$
B=\frac{H}{\mathrm{LE}}
$$

and, assuming equality between the eddy diffusivities for enthalpy and water vapor (Ohmura 1982a), is approximated by

$$
B=\frac{C_{p} \Delta T}{L \Delta q} .
$$

Here, $C_{p}$ denotes the specific heat at constant pressure, $L$ the latent heat of vaporization, $T$ the temperature, and $q$ the specific humidity. Introducing (2) in (1) yields

$$
\mathrm{NR}+G+\mathrm{LE}(1+B)=0 \text {. }
$$

Equations (2) and (4) together define the turbulent energy fluxes as

$$
\mathrm{LE}=\frac{1}{1+B}(\mathrm{NR}+G),
$$

and

$$
H=\frac{B}{1+B}(\mathrm{NR}+G) .
$$

Measurements of the net radiation and of the ground 
heat flux were carried out at both study sites with the same types of instruments. Net radiation was measured at $1.5 \mathrm{~m}$ above the surface with a Funk-type net radiometer. Due to a possible underestimation by the Funktype net radiometer (Konzelmann and Ohmura 1995), net radiation was corrected accordingly. In addition, upand downfacing pyranometers were used to monitor the global and shortwave reflected radiation, respectively. For a better interpretation of radiative fluxes, cloud observations, including amount and types, were made at 3-h intervals during daytime. The ground heat flux was monitored with three soil heat flux disks of the Thornthwaite type. The sensors were buried at a depth of approximately $1 \mathrm{~cm}$ to minimize heat flux divergence (Mayocchi and Bristow 1995).

Air temperature and relative humidity were monitored at three levels $(0.5,1$, and $2 \mathrm{~m})$ using resistance and capacity sensors, respectively. All sensors were ventilated. In addition, at the upper site, air temperature and dewpoint were measured at 0.5 and $2 \mathrm{~m}$ with dewpoint sensors. Due to their higher reliability, these latter were used for reference. All calculations were based on the data gathered at 0.5 and $2 \mathrm{~m}$. A relative calibration of all profile sensors was performed at the beginning and at the end of the field campaign.

Unrealistic values of the Bowen ratio were rejected according to the objective criteria formulated by Ohmura (1982b). As expected, most of the problematic cases occurred in the early morning, late afternoon, and night, when the direction of latent heat flux was opposite to that of sensible heat flux and when the turbulent fluxes were small in magnitude. To produce a complete dataset, monthly averages of $B$ based on all remaining halfhourly values were used to recalculate missing values of LE and $H$ (Müller 1989).

The relative uncertainty in the computed hourly values of the turbulent fluxes was estimated to range between $10 \%$ and $20 \%$. This can be seen by assuming typical daytime values for the relevant quantities as $\mid N R$ $+G\left|\sim 250 \pm 15 \mathrm{~W} \mathrm{~m}^{-2} ;\right| \Delta T \mid \sim 0.8^{\circ} \pm 0.05^{\circ} \mathrm{C}$; and $|\Delta q| \sim 0.0008 \pm 0.0001 \mathrm{~kg} \mathrm{~kg}^{-1}$, which yields $|B| \sim$ $0.4 \pm 0.1$ and $|\mathrm{LE}| \sim 180 \pm 30 \mathrm{~W} \mathrm{~m}^{-2}$.

\section{The energy balance}

Daily mean values of the energy-balance components at Stillberg and Teufi are depicted in Figs. $2 a$ and $2 b$, respectively. Mean daily values of measured and derived quantities are summarized in Table 1. On most of the days net radiation is the only energy source. In August it averages to about $80 \mathrm{~W} \mathrm{~m}^{-2}$ at Teufi and $100 \mathrm{~W} \mathrm{~m}^{-2}$ at Stillberg. This difference reflects the different height of the horizon, which is $12^{\circ}$ in average at Stillberg, compared to the $23^{\circ}$ at Teufi. Due to the lower horizon, in fact, diffuse sky radiation is substantially larger at Stillberg. This results in a larger global radiation and finally, since differences in the albedo and in the longwave radiation balance are minimal, in a larger net ra- diation. A very good linear correspondence was observed between global and net radiation, with correlation coefficients and slopes of regression lines of 0.984 and 0.752 and 0.995 and 0.705 for Stillberg and Teufi, respectively. These results support the findings of other studies (Davies 1967; Nielsen et al. 1981).

Of the energy sinks, the ground heat flux is the least important at Stillberg, where it consumes only $3 \%$ of the energy supplied by the net radiative flux. At Teufi, it is of comparable magnitude to the sensible heat flux, depleting $6 \%$ of the energy input. At both sites, latent heat represents the largest energy sink during most of the time. It corresponds in magnitude to about $65 \%$ of the energy input at Stillberg but about $85 \%$ at Teufi. This latter value is comparable to those derived for other locations in the prealpine and alpine region where meadow is the dominant vegetation type (Müller 1989; Bernath 1990).

Daily mean values of the net radiation and the sensible and the latent heat flux for Teufi and Stillberg are compared in Figs. 3a-c, respectively. The most striking feature is the departure of the points' cloud from the $1: 1$ line in the plot of the sensible heat flux. A closer inspection reveals, however, that similar differences characterize the plot of the net radiation. On the other hand there are no obvious departures from the 1:1 line in the case of the latent heat flux. This means that any surplus of net radiation at Stillberg is depleted in the form of sensible heat (Fig. 4).

Since the partition between the two turbulent fluxes is determined by the Bowen ratio, what was described in the previous paragraph should be examined considering this parameter. Mean daily courses of the energy flux components and of the Bowen ratio for August are given in Fig. 5. At Stillberg, during day, the Bowen ratio ranges from 0.6 to 0.8 , and the two turbulent fluxes are indeed of comparable magnitude from sunrise to sunset. At Teufi the Bowen ratio is much smaller. It displays a more pronounced daily variability, with values around 0.2 in the morning hours and a steady decrease during the afternoon. This results in a more pronounced daily cycle of the latent heat flux at Teufi (Fig. 5 ). The values of the Bowen ratio at Teufi are, on average, slightly smaller than those given by Rott (1979) for meadow, which range from 0.2 to 0.6 .

At both sites the daily course of the latent heat flux closely reflects that of net radiation in a number of details. It is therefore in order to examine the relation between latent heat flux and net radiation more carefully, limiting the analysis to the hours between sunrise and sunset. The comparison is shown in Fig. 6. At both sites, the correlation coefficient is high and the intercept of the linear regression line does not depart significantly from zero.

The slopes of the regression lines are consistent with the observed values of the Bowen ratio (Table 1). Note, however, that, as seen in Eq. (5), it is the factor $(1+$ $B)^{-1}$ rather than $B$ that connects LE to NR. Simple ar- 

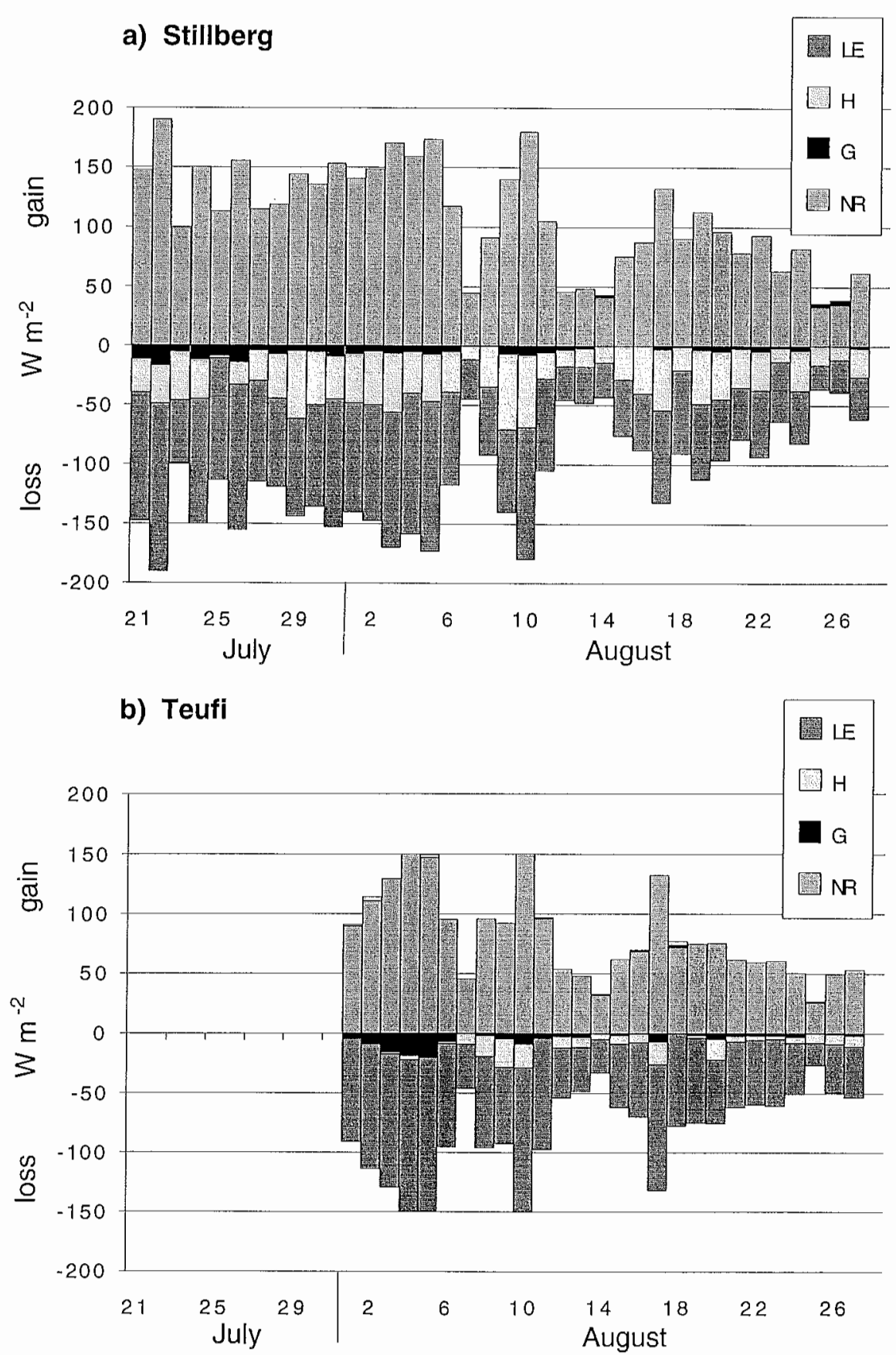

Fig. 2. Daily mean values of the energy flux components for (a) Stillberg and (b) Teufi: NR is net radiation, $G$ is ground heat flux, $H$ is sensible heat flux, and LE is latent heat flux. Fluxes are defined to be positive toward the surface. Measuring periods for (a) 21.7.-27.8.95 and (b) 1.8.28.8.95. Units are watts per square meter.

guments suggest that for a daily course of the Bowen ratio as shown in Fig. 5 the factor $(1+B)^{-1}$ becomes nearly a constant. More pragmatically, daytime hourly data for the whole month of August give for $(1+B)^{-1}$ a coefficient of variation of 0.2 at Stillberg (mean: 0.60 ; standard deviation: 0.12 ) and 0.1 at Teufi (mean: 0.83 ; standard deviation: 0.09).
In view of the high correlation between net and global radiation, it is instructive to examine the dependence of the latent heat flux on global radiation, which is one of the most often observed and most accurately determined energy fluxes at the surface (Müller 1985). The relation is shown in Fig. 6. As expected, the correlation coefficient is high at both sites. 
TABLE 1. Mean daily values of meteorological components observed from 1 to 27 August in the Dischma Valley at Stillberg, 2220 $\mathrm{m}$ MSL and Teufi, $1680 \mathrm{~m}$ MSL. Positive values refer to a gain of energy at the surface, negative values to an energy loss. Energy fluxes are expressed in watts per square meter.

\begin{tabular}{lcc}
\hline \hline & Stillberg & Teufi \\
\hline Global radiation & 177.3 & 156.4 \\
SW reflected radiation & -34.3 & -33.0 \\
SW balance & 143.0 & 123.4 \\
Albedo & 0.194 & 0.211 \\
LW balance & -44.9 & -42.5 \\
Net radiation & 98.1 & 80.9 \\
Ground heat flux & -2.7 & -4.5 \\
Sensible heat flux & -32.3 & -6.8 \\
Latent heat flux & -63.1 & -69.6 \\
Bowen ratio (dimensionless) & 0.51 & 0.10 \\
Temperature at 2 m ( $\left.{ }^{\circ} \mathrm{C}\right)$ & 9.0 & 10.4 \\
Relative humidity at $2 \mathrm{~m}(\%)$ & 78.8 & 77.7 \\
Total precipitation (mm) & 126 & 111 \\
Total cloud amount $(\%)$ & 75 & - \\
\hline
\end{tabular}

\section{Evapotranspiration}

As described in section 2, the last three weeks of August were characterized by frequent rainfall, with nearly identical total amounts at the two stations. At first sight it therefore appears that saturated surface conditions could have been expected on most days at both sites. In this case the actual evapotranspiration should have been very close to the limit given by Penman's (1948) parameterization. This is later often referred to as potential evapotranspiration, although it effectively represents the potential limit only for a saturated surface (e.g., Brutsaert 1982 and Garratt 1992). It reads

$$
\mathrm{ET}_{P}=\frac{\Delta}{\Delta+\gamma}(\mathrm{NR}+G)+\frac{\gamma}{\Delta+\gamma} E_{A} .
$$

Here, $\Delta=\left(d e_{a}^{*} / d T\right)$ denotes the slope of the saturation vapor pressure curve at air temperature, and $\gamma=$ $0.622 C_{p} / p L$ is the psychrometric constant. The first term on the right-hand side of (7) is usually referred to as the "equilibrium evaporation" (see discussion in Crago and Brutsaert 1992). Here, $E_{A}$ represents the ventilation or aerodynamic term, given by Penman (1948) as $E_{A}=$ $0.26\left(1+0.54 U_{2}\right)\left(e_{a}^{*}-e_{a}\right)$, where $U_{2}\left(\mathrm{~m} \mathrm{~s}^{-1}\right)$ is the wind speed at $2 \mathrm{~m}, e_{a}$ and $e_{a}^{*}$, both in hectopascals, are the actual and saturation vapor pressure, respectively.

The validity of Penman's formulation of the ventilation term is discussed for instance in Thom and Oliver (1977). Here it is sufficient to remark that for the conditions observed during the field campaign the ventilation term only amounts to about $10 \%$ of the equilibrium term. Thus, since the actual evapotranspiration is comparable at both sites and so is the slope of the saturation pressure curve, the ratio of the actual to the parameterized evapotranspiration becomes only a function of the energy supply given by the term (NR $+G)$. This ratio is about 1.0 at Teufi and 0.8 and Stillberg.

Time series of the daily total precipitation and of the daily average difference between the measured evapo-
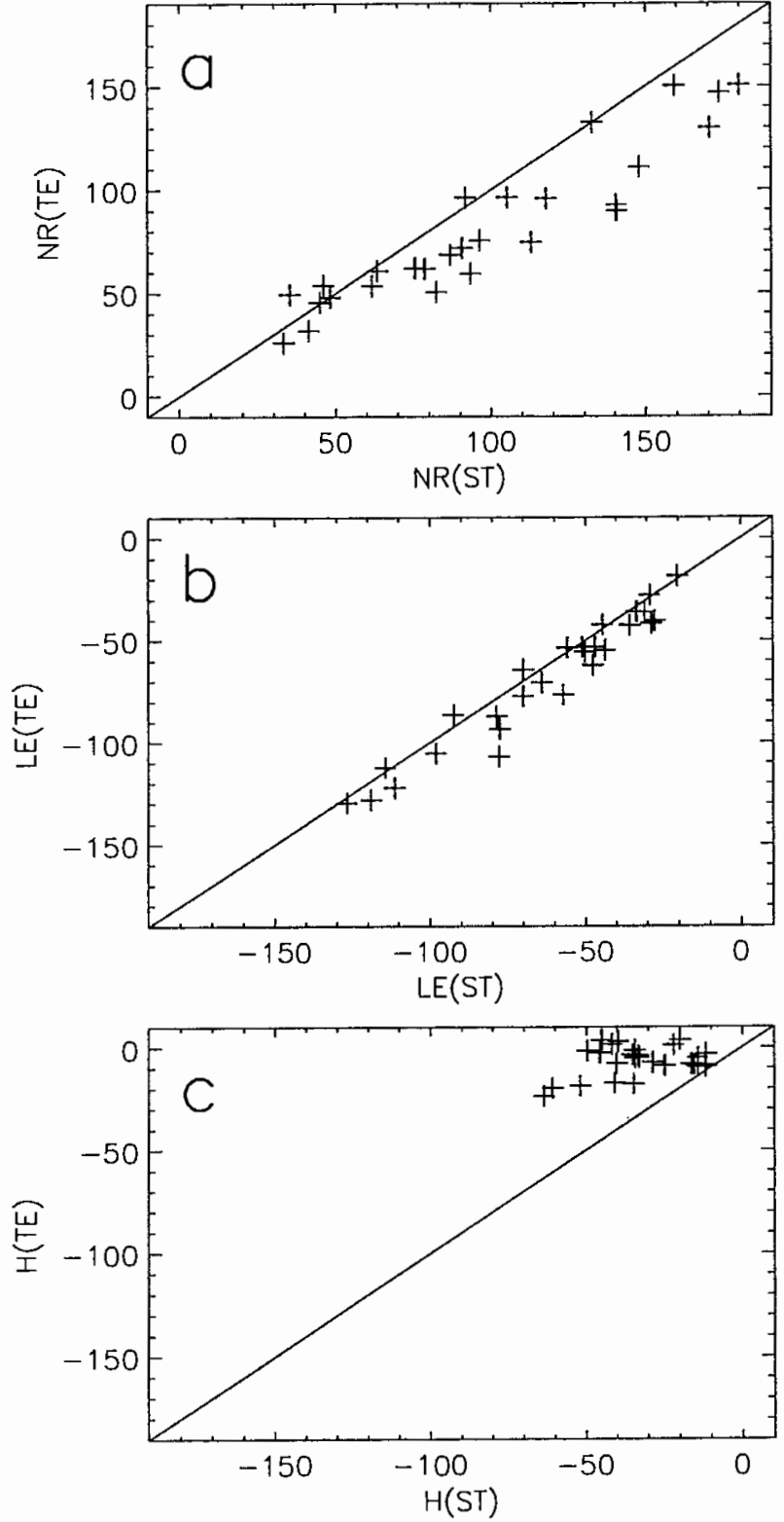

FIG, 3. Relationship between daily mean values of the observed energy fluxes at Stillberg (ST, abscissa) and Teufi (TE, ordinate) for the period 1-27 August 1995: (a) NR is net radiation, (b) LE is latent heat flux, and (c) $H$ is sensible heat flux. In each plot the $1: 1$ lines are given. Units are watts per square meter.

transpiration and Penman's parameterization (this latter average being computed only for hours between sunrise and sunset) are displayed in Fig. 7. Accounting for all possible sources of errors, at Teufi the difference between the actual evapotranspiration and Penman's parameterization can be assumed to be effectively zero at all days. Not so at Stillberg, where it approaches zero only at all days following rain events. On occasions with little or no precipitation, the actual evapotranspiration becomes significantly smaller than the limit given by Penman's parameterization. Nevertheless, the dif- 


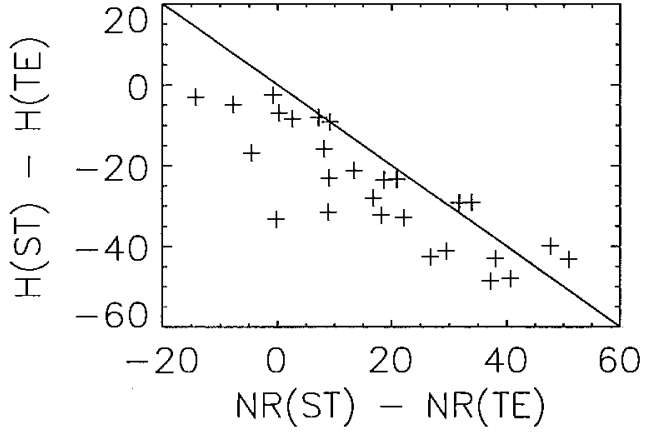

FIG. 4. Relationship between daily mean values of the differences of net radiation (NR) and sensible heat flux $(H)$ at Stillberg (ST) and Teufi (TE), respectively. Units are watts per square meter.

ference becomes less and less substantial as more precipitation events accumulate.

These findings support the view that in an alpine environment evapotranspiration is primarily controlled by the moisture conditions in the soil and the plants even during wet periods. At Teufi, where the dominant vegetation type is meadow and the soil is compact, saturated conditions prevail for several days after termination of rainfall and evapotranspiration is only limited by the availability of energy. This is in very good agreement with results from the prealpine region obtained for similar surface conditions (Müller 1989).

At Stillberg, on the other hand, a faster percolation through the thinner soil layer and a more effective water storage in dwarf shrubs appear to be plausible reasons for the observed characteristics of the actual evapotranspiration. Provisional data gathered at the two sites during the field campaign show a smaller soil field capacity at Stillberg than at Teufi (P. Hofmann 1996, personal communication). Concerning the physiological behavior of the vegetation, it is known that large variations in leaf conduction are to be expected in an alpine environment (Körner and Mayr 1981, their Table 11.2). Dwarf shrubs, which prevail at Stillberg, have a very low leaf conduction compared to meadow-type vegetation. Low conduction implies a large surface resistance and consequently a low transpiration rate (Oke 1987).

Not having direct measurements of the relevant parameters (see Garratt 1992), an estimate of the surface resistance can be obtained from the following equation given in Szeicz and Long (1969) and originally proposed by Monteith (1965) for daylight conditions and a completely vegetated surface:

$$
\log _{10} r_{s}=3.4+2 \mathrm{LE}(\mathrm{NR}+G)^{-1} .
$$

Mean values of 55 and $178 \mathrm{~s} \mathrm{~m}^{-1}$ are computed for Teufi and Stillberg, respectively. The difference is indeed significant. The value for Teufi corresponds well to observations made over grassland (Wallace 1995). The higher value at Stillberg cannot be verified directly. An indication that it is at least correct in orders of magnitude is provided by estimates of the actual evapotranspiration computed with the Penman-Monteith equation (Oke
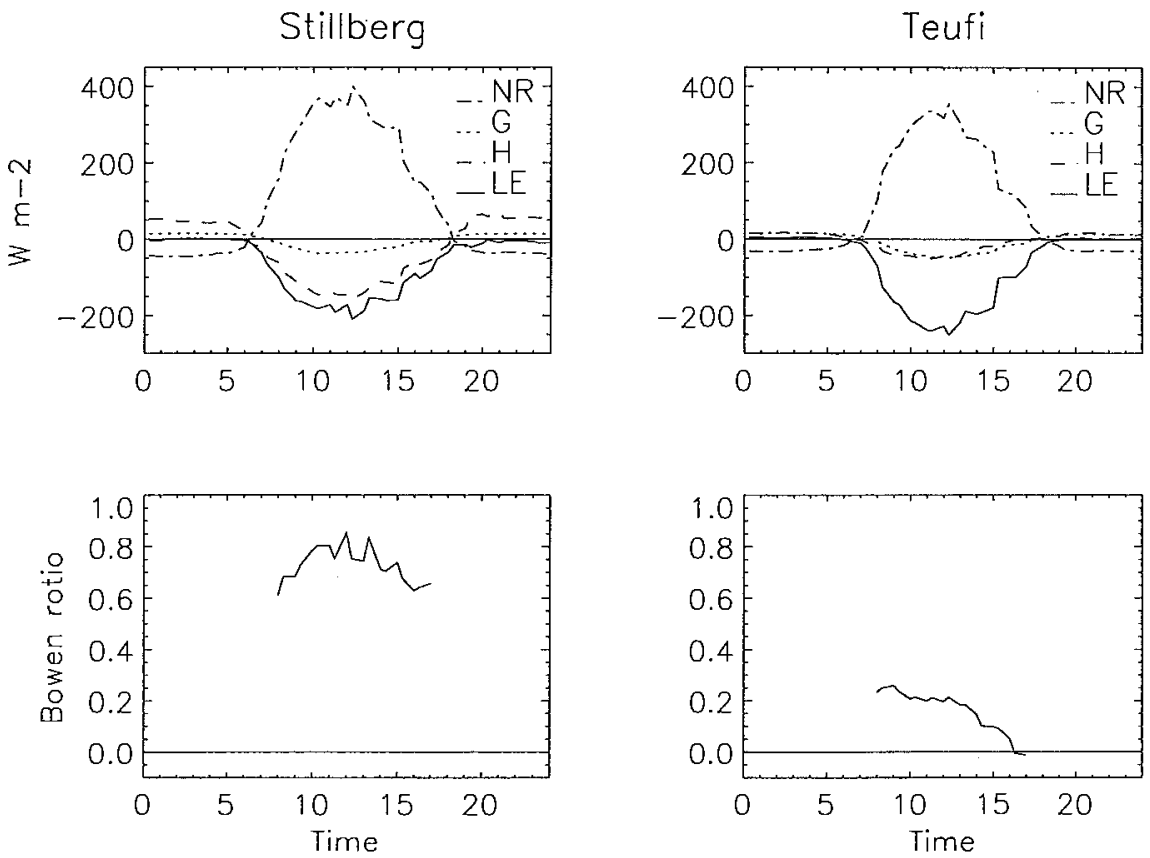

FIG. 5. Mean daily courses of the energy fluxes and the Bowen ratio for August 1995 at Stillberg and Teufi. Bowen ratio is given for daylight hours only: NR is net radiation, $G$ is ground heat flux, $H$ is sensible heat flux, and LE is latent heat flux. Fluxes are defined to be positive toward the surface. Time corresponds to local standard time (LST). 
Stillberg
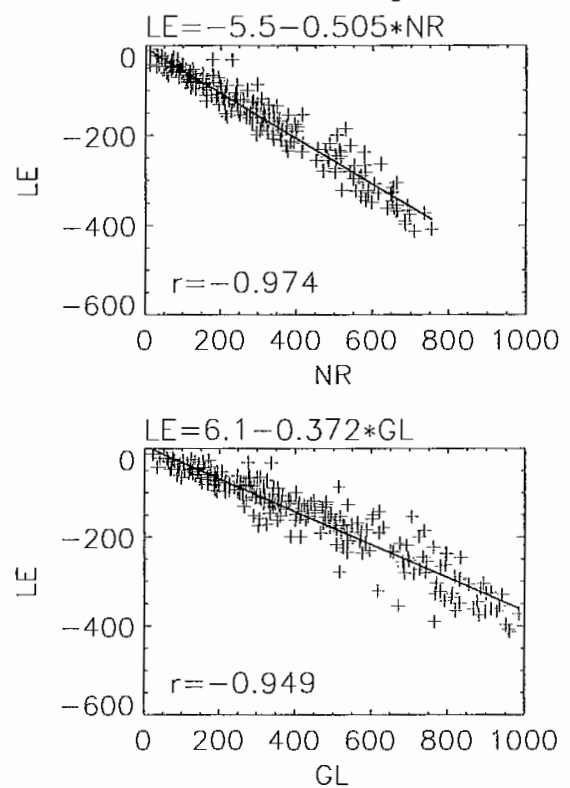

Teufi
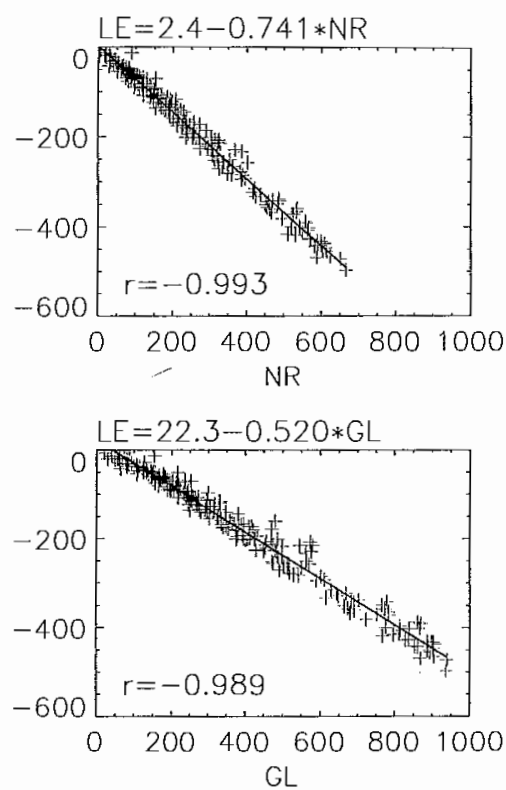

FIG. 6. Dependence of latent heat flux (LE) on net radiation (NR, upper frames) and global radiation (GL, lower frames) for Stillberg (left) and Teuf (right). Displayed are hourly values between 0800 and 1700 LST for the period 1-27 August. Fluxes are defined to be positive toward the surface. The equations of the regression lines and the correlation coefficients are given.

1987) and values of the surface resistance given by (8). These estimates are close to the observed values.

\section{Summary and conclusions}

A field campaign was conducted in August 1995 to investigate the energy balance and the evapotranspiration in a high alpine region. Measurements were carried out at two sites characterized by different physiographic con- ditions. Net radiation is the only energy source at both observation sites. It is larger by about $20 \%$ at the upper site, because of a larger amount of sky visible. The ground heat flux is relatively small but cannot be neglected. At the upper site approximately $65 \%$ of net radiation is depleted by the latent heat flux associated with evapotranspiration, while at the lower site, where the Bowen ratio is significantly smaller, this ratio increases to more than $85 \%$. Thus, the surplus of available energy
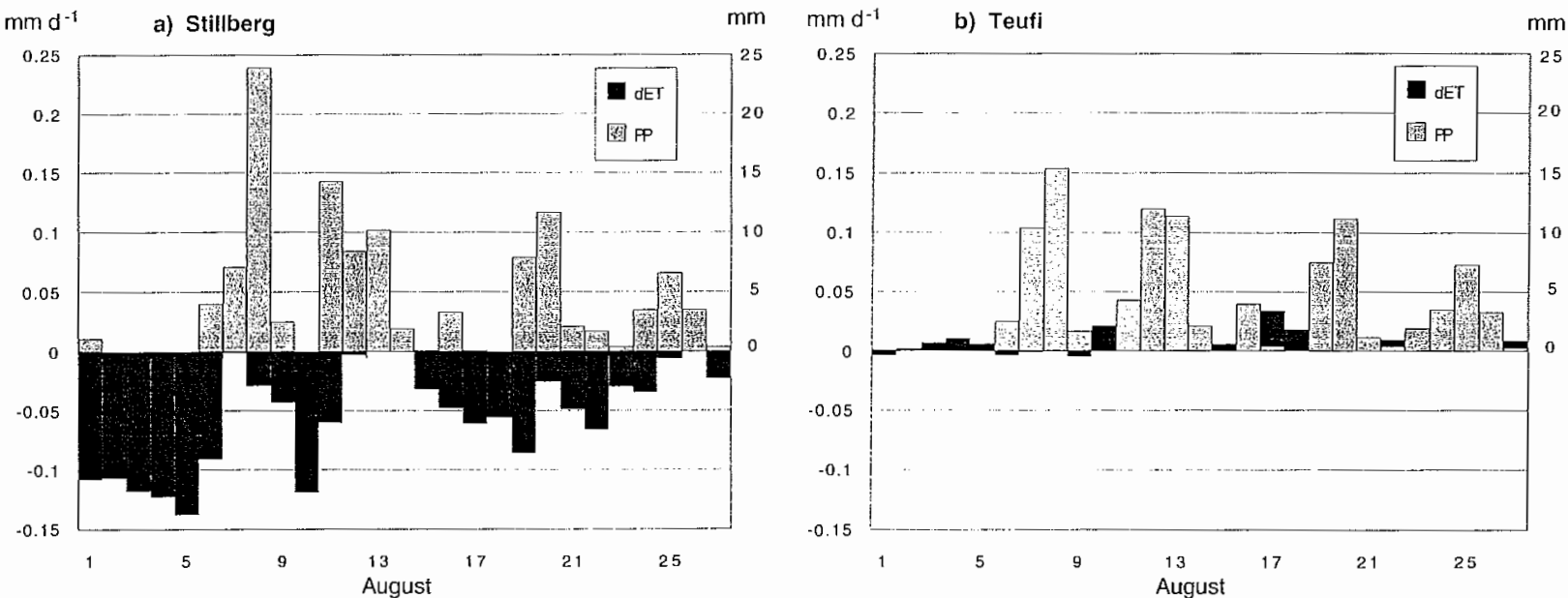

FIG. 7. Time series of the differences of actual minus potential evapotranspiration (dET) and precipitation (PP) for (a) Stillberg and (b) Teufi. Displayed are daytime mean values between 0800 and 1700 LST for the period 1-27 August. Left scale corresponds to dET (mm day $^{-1}$ ), right scale to precipitation $(\mathrm{mm})$. 
at the upper site is balanced exclusively by the sensible heat flux. At both sites, the latent heat flux can be well expressed as a linear function of global or net radiation.

The values of actual evapotranspiration favorably correlate with those computed with Penman's formulation. For saturated surface conditions Penman's parameterization represents the potential evapotranspiration. Potential evapotranspiration was expected on most days, since frequent rainfall was observed during the field campaign. This was the case at Teufi, where meadows prevail. On the other hand, the observed values of the evapotranspiration were consistently lower than those of Penman's parameterization at the upper site, indicating a larger surface resistance and an active control by the biosphere even during relatively wet periods. It is concluded that the type of vegetation and surface texture has to be considered more carefully for model calculations of the evapotranspiration in high mountain areas.

At the two study sites, well-defined linear relations between the latent heat flux and net or global radiation, and between the actual and potential evapotranspiration, could be found. If this proves valid for larger areas and different vegetation types, a promising solution for the estimation of regional evapotranspiration in alpine terrain by routine meteorological observations is indicated.

Acknowledgments. The authors are very grateful to all the people participating in the Dischma project. The logistic infrastructure was made available by the Swiss Federal Institute for Snow and Avalanche Research (SLF) and the Swiss Federal Institute for Forest, Snow, and Landscape Research (WSL). Special thanks are due to Dr. R. Häsler (WSL). K. Schroff prepared all the instruments. Thanks are also extended to Dr. P. Hofer of the Swiss Federal Laboratories for Materials Testing and Research (EMPA) for allowing one of the authors (P. Calanca) to participate in the project. The research was supported by the Swiss Federal Institute of Technology (ETH), Zurich (Grants 0-20-978-95 and 0-20-042-95).

\section{REFERENCES}

Bailey, W. G., I. R. Saunders, and J. D. Bowers, 1990: Atmosphere and surface control on evaporation from alpine tundra in the Canadian Cordillera. Hydrology in Mountainous Regions I, $\mathrm{H}$. Lang and A. Musy, Eds., IAHS Publ. 193, 45-52.

Barry, R. G., 1992: Mountain Weather and Climate. Routledge, 402 pp.

Bernath, A., 1990: Evaporation measurements in the Alpine basin Gletsch during the ALPEX/RHONEX project. Hydrology in Mountainous Regions I, H. Lang and A. Musy, Eds., IAHS Publ. 193, 53-60

Brutsaert, W., 1982: Evaporation into the Atmosphere. Reidel, 299 pp.

, and W. P. Kustas, 1987: Surface water vapor and momentum fluxes under unstable conditions from a rugged-complex area. J. Atmos. Sci., 44, 421-431.

Crago, R. D., and W. Brutsaert, 1992: A comparison of several evaporation equations. Water Resour: Res., 28, 951-954.

Davies, J. A., 1967: A note on the relationship between net radiation and solar radiation. Quart. J. Roy. Meteor. Soc., 93, 109-115.
Garratt, J. R., 1992: The Atmospheric Boundary Layer, Cambridge University Press, $316 \mathrm{pp}$

Grebner, D., and W. Brutsaert, Eds., 1984: The EVAPEX-ALPEX Campaign 1982-Hydrological and Meteorological Studies in the Pre-Alpine Research Basin Rietholzbach. Zürcher Geographische Schriften, 18, Geographisches Institut ETH Zürich, 201 pp. [Available from Geographie ETH, Winterthurerstr. 190, $\mathrm{CH}-8057$ Zürich, Switzerland.]

Gurtz, J., A. Baltensweiler, H. Lang, and J. Schulla, 1997: Spatial distributed model approaches to hydrologic processes and river flow from mountainous regions. Proc. Int. Conf. on Ecohydrology of High Mountain Areas, Kathmandu, Nepal, UNESCO/ WMO/IAHS/IGBP-BAHC, in press.

Hennemuth, B., and U. Köhler, 1984: Estimation of the energy balance of the Dischma Valley. Arch. Meteor. Geophys. Bioklimatol., Ser. B, 34, 97-119.

Konzelmann, T., and A. Ohmura, 1995: Radiative fluxes and their impact on the energy balance of the Greenland ice sheet. $J$. Glaciol., 41, 490-502.

Körner, C., and R. Mayr, 1981: Stomatal behaviour in alpine plant communities between 600 and 2600 meters above sea level. Plants and Their Atmospheric Environments, J. Grace, E. D. Ford, and P. G. Jarvis, Eds., Blackwell Scientific Publishers, 205218.

Lang, H., 1978: Zum Problem der räumlichen und zeitlichen Variabilität der Verdunstung in der Schweiz. Beitr. Geol. Schweiz Hydrol., 25, 53-61.

LeDrew, E. F, 1975: The energy balance of a mid-latitude alpine site during the growing season, 1973. Arc. Alp. Res., 7, 301-314.

Mayocchi, C. L., and K. L. Bristow, 1995: Soil surface heat flux: Some general questions and comments on measurements. Agric. Forest Meteor, 75, 43-50.

Monteith, J. L., 1965: Evaporation and environment. Symp. Soc. Exp. Biol, 19, 205-234.

Müller, G., 1989: Methodische Untersuchungen zur Bestimmung der Verdunstung im Voralpinen Raum. Zürcher Geographische Schriften, 36, Geographisches Institut ETH Zürich, 224 pp. [Available from Geographie ETH, Winterthurerstr. 190 , CH-8057 Zürich, Switzerland.]

Müller, H., 1985: On the radiation budget in the Alps. J. Climatol., 5, 446-462.

Nielsen, L. B., L. P. Prahm, R. Berkowicz, and K. Conradsen, 1981: Net incoming radiation estimated from hourly global radiation and/or cloud observations. J. Climatol., 1, 255-272.

Ohmura, A., 1982a: Evaporation from the surface of the Arctic tundra on Axel Heiberg Island. Water Resour. Res., 18, 291-300.

… 1982b: Objective criteria for rejecting data for ratio flux calculations. J. Appl. Meteor., 21, 595-598.

Oke, T. R., 1987: Boundary Layer Climates. Routledge, 435 pp.

Penman, H. L., 1948: Natural evaporation from open water, bare soil and grass. Proc. Roy. Soc. London, A193, 120-145.

Plïss, C., and R. Mazzoni, 1994: The role of turbulent heat fluxes in the energy balance of high alpine snow cover. Nordic Hydrol. $25,25-38$.

Rott, H., 1979: Vergleichende Untersuchungen der Energiebilanz im Hochgebirge. Arch. Meteor. Geophys. Bioklimatol., Ser. A, 28, $211-232$.

Staudinger, M., and H. Rott, 1981: Evapotranspiration at two mountain sites during the vegetation period. Nordic Hydrol., 12, $207-$ 216

Szeicz, G., and I. F. Long, 1969: Surface resistance of crop canopies. Water Resour. Res., 5, 622-633.

Thom, A. S., and H. R. Oliver, 1977: On Penman's equation for estimating regional evaporation. Quart, J. Roy. Meteor. Soc. 103, 345-357.

Turner, H., P. Rochat, and A. Streule, 1975: Thermische Charakteristik von Hauptstandortstypen im Bereich der oberen Waldgrenze. Mitt. Eidg. Anstalt Forstl. Versuchswesen, 51, 95-119.

Wallace, J. S., 1995: Calculating evaporation: Resistance to factors. Agric. Forest Meteor., 73, 353-366. 
